\title{
Correction to: In vitro effects of curcumin on proinflammatory cytokines and expression of their genes in minor salivary gland tissue of patients with Sjogren's syndrome
}

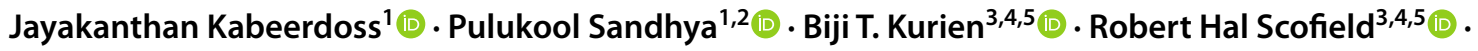 \\ Debashish Danda ${ }^{1}[$
}

Published online: 8 May 2021

(c) Springer-Verlag GmbH Germany, part of Springer Nature 2021

\section{Correction to: Rheumatology International https://doi.org/10.1007/s00296-021-04859-7}

In the original article, the abstract section is published incorrectly. The correct abstract is given below.

\begin{abstract}
Curcumin reduces disease severity and ameliorates lupuslike/Sjögren's Syndrome-like disease in mice model. The immunological basis of these effects is largely unknown. This study examined the effects of curcumin on proinflammatory cytokines secreted by minor salivary glands in patients with primary Sjögren's syndrome (pSS). Minor salivary gland (MSG) tissue samples were collected from patients undergoing biopsy for suspected pSS. The tissues were treated with phytohemagglutinin (PHA) alone as well as PHA with curcumin $(30 \mu \mathrm{M})$ and cultured in RPMI 1640 medium for $48 \mathrm{~h}$ at $37^{\circ} \mathrm{C}$ in $\mathrm{CO}_{2}$ incubator.
\end{abstract}

The original article can be found online at https://doi.org/10.1007/ s00296-021-04859-7.

Debashish Danda

debashisdandacmc@hotmail.com

1 Department of Clinical Immunology and Rheumatology, Christian Medical College and Hospital, Vellore, Tamil Nadu 632004, India

2 Present Address: Department of Rheumatology, St Stephen's Hospital, Tis Hazari, Delhi 110054, India

3 Arthritis and Clinical Immunology Research Program, Oklahoma Medical Research Foundation, Oklahoma City, OK, USA

4 Department of Medicine, University of Oklahoma Health Sciences Center, Oklahoma City, OK, USA

5 Department of Veterans Affairs Medical Center, Oklahoma City, OK, USA
After the incubation period, culture supernatant and tissues were stored in the freezer $\left(-80^{\circ} \mathrm{C}\right)$. IL-6 levels were measured in supernatant by ELISA kit. Gene expressions of pro-inflammatory cytokines, namely IL-6, IL- 8 , TNF- $\alpha$, IL-1 $\beta$, IL-4, IL-10, IL-17, IL-21, and IFN- $\gamma$, were measured by qPCR. IL-6 secretion levels and gene expressions were compared statistically between groups by Student's t test. Forty-seven patients were screened. Eight patients satisfied ACR/EULAR criteria for pSS. Seven patients with absent glandular inflammation and negative serology constituted sicca controls. These 15 subjects were included in final analysis. In pSS group, but not in controls, median IL-6 levels in supernatant were less in curcumin-treated as compared to PHA-alone subset [5.5 (0.7-13.34) vs $18.3(12-32) \mathrm{ng} /$ $\mathrm{ml} ; p=0.0156]$. mRNA expression levels of IL-6 were also lower in curcumin-treated samples as compared to PHA alone, when cases and controls were analyzed together as well as in cases alone ( $p=0.0009$ and $p=0.0078$, respectively); however, mRNA expression of IL- $1 \beta$ was lower in curcumin-treated samples as compared to PHA alone, only when cases and controls were analyzed together $(p=0.0215)$. There was no difference in other cytokine gene expression levels between the subsets under the in-vitro experimental conditions. In conclusion, curcumin reduced mRNA expression as well as secretion of IL-6 levels by salivary gland tissue of patients with pSS. Curcumin also suppressed PHA-induced mRNA expression levels of IL-6 and IL- $1 \beta$ in MSG tissue of patients with pSS and controls when analyzed together as a combined group.

The original article has been corrected.

Publisher's Note Springer Nature remains neutral with regard to jurisdictional claims in published maps and institutional affiliations. 